\title{
Efficiency of European Airports: Parametric Versus Non-parametric Approach
}

\author{
Markéta Matulová $^{1, *}$, and Jana Rejentová ${ }^{2}$ \\ ${ }^{1}$ Faculty of Economics and Administration, Masaryk University, Lipová 41a, Brno, Czech Republic \\ E-mail: 〈Marketa.Matulova@econ.muni.cz〉 \\ ${ }^{2}$ Faculty of Economics and Administration, Masaryk University, Lipová 41a, Brno, Czech Republic \\ E-mail: 〈436972@mail.muni.cz〉
}

\begin{abstract}
This paper presents a performance evaluation of European airports, based on the application of both parametric and non-parametric approaches. We have evaluated the 115 busiest airports in Europe according to the number of passengers checked-in in 2018. The four inputs we used were the number of Terminals, Runways, Boarding gates, and Aircraft stands. Three variables were used to describe the outputs, namely, Passengers, Movements, and Cargo. The parametric method we chose to apply was the Stochastic Frontier Analysis (SFA) with the Cobb-Douglas production function, the Half-Normal distribution of inefficiency component, and the Normal distribution of an error term. As a basic SFA model only allows for a single output, we employed different methods to get a single efficiency score for each and every airport. Next, we evaluated the airport performance non-parametrically using several Data Envelope Analysis (DEA) models including the super-efficiency model. We compared the results obtained by individual approaches and discussed their pros and cons. Finally, we applied the program evaluation procedure to explore the effect of the different forms of airports ownership on their performance.
\end{abstract}

Keywords: airport efficiency, data envelopment analysis, stochastic frontier analysis

Received: November 16, 2020; accepted: January 07, 2021; available online: June 29, 2021

DOI: $10.17535 /$ crorr.2021.0001

\section{Introduction}

Airport benchmarking serves the stakeholders as a useful tool to support their decision-making. Managers can use it to identify the best practice and develop new concepts for improvement, and governments can assess the impact of their policy decisions. The aviation industry has developed rapidly over the last years, and different ways of managing airports have evolved bringing with them the opportunity for the application of various benchmarking techniques. Our study evaluates the relative efficiency of 115 European airports using the data from the year 2018.

One of the essential factors determining airport performance is the form of ownership. In the past, most airports were publicly owned, which is still true in some cases. However, during the last two decades of the 20th century, privatization took place in many countries. With this change, competition between airports has also begun to grow. However, the majority of privatized airports in Europe remains subject to some extent of economic regulation [9]. Current measures taken by European countries connected to the coronavirus pandemic will have a severe impact on transportation companies including airlines and airports. Some governments plan to

${ }^{*}$ Corresponding author. 
nationalize major airlines to save them from bankruptcy and similar measures may affect the airports. The change in the airports' ownership may well have a significant impact on their productivity and efficiency. So, in the final part of our analysis, we compare the performance of airports with different forms of ownership.

The paper is organized as follows: A review of already published works in the area of airport efficiency and the effect of ownership is presented in the second section. The models for evaluating efficiency and statistical analysis are described in the third section and the data sample in the fourth section. The results are presented and discussed in the fifth section, and the last section is the conclusion.

\section{Literature review}

Since the late 1990s, a lot of academic research has emerged applying quantitative approaches to assessing the productivity and efficiency of airports. The major studies on large European airports are represented by Pels et al., [18, 19]. The authors perform analyses separately for two different outputs for 33 European airports in 1995-1997. They use SFA to estimate the production limit for the number of aircraft movements, obtain predicted values of aircraft movements and then use these as another explanatory variable for the number of passengers carried. Liebert mentions 38 studies in her survey [11] which apply parametric methodology (mostly stochastic frontier analysis) and 29 nonparametric studies (mostly data envelopment analysis). Some authors, however, debate the relevance of airport performance evaluation due to inconsistencies in the data selection and model specifications which result in limited value for managers. Different techniques and the airports' heterogeneous character may lead to controversies across studies [12]. Most of the research has been limited in the number of units compared, and the regional specification; only 10 papers out of 67 covered by the survey of Liebert [11] are based on the sample of European airports, and their number ranges only from 25 to 48 , so our article aims to fill this gap.

Many empirical studies have analyzed the effects of different ownership forms on efficiency, but the results have not led to any clear conclusions. Parker [17] utilizes DEA to estimate the technical efficiency of the British airports covering the period pre and post-privatization. He finds no evidence that complete privatization leads to improved technical efficiency. Barros and Dieke [5] analyze data on 31 Italian airports from 2001 to 2003 to reveal that private airports operate more efficiently than their partially private counterparts. However, Lin and Hong [13] find no connection between ownership form and efficiency after analyzing a data set of worldwide airports for the years 2001 and 2002. The results by Vogel [24] on a European set of airports reveal that privatized airports operate more cost efficiently and receive higher returns on total assets and revenues. Public airports, in turn, had the advantage of higher gearing and financial leverage. Oum et al. [15] distinguish between public airports owned by public corporations and those owned by more than one public shareholder and conclude that different ownership and governance structures affect the quality of managerial performance. Conversely, Oum et al. [16] assess a sample of 100 airports worldwide covering the years 2001 to 2003, and they reach the conclusion that the productivity of a public corporation is not significantly different from that of a major private airport. So, the effect of ownership on airports' efficiency so far remains an open question, and with our paper we aim to add to this debate.

\section{Methodology}

The parametric approach is represented in our analysis by the stochastic frontier analysis. In the following subsection, we describe the setting of our SFA model and various approaches used to aggregate results obtained for the separate outputs into a single measure of inefficiency. 
Then we present several selected models of data envelopment analysis in the subsection on non-parametric approaches.

\subsection{Stochastic frontier analysis}

The stochastic frontier model for one output assumes production function of the form

$$
y_{i}=f\left(x_{i} ; \beta\right) \cdot \exp \left(v_{i}\right) \cdot \exp \left(-u_{i}\right), i=1, \ldots, n,
$$

where $y_{i}$ is the level of the output and $x_{i}$ is an input vector for $i$-th unit, $v_{i}$ is symmetric random error, and $u_{i}$ is nonnegative term representing technical inefficiency, $i=1, \ldots, n$.

Cobb-Douglas production function was chosen as a suitable functional form for our data:

$$
f\left(x_{i} ; \beta\right)=\beta_{0} \prod_{j=1}^{m} x_{i j}^{\beta_{j}}
$$

The stochastic components of our model (random errors and inefficiencies) were supposed to have Normal and Half-Normal distributions with following assumptions:

1. $v_{i} \sim \operatorname{iid} N\left(0, \sigma_{v}^{2}\right)$,

2. $u_{i} \sim \operatorname{iid} N^{+}\left(0, \sigma_{u}^{2}\right)$,

3. $u_{i}$ and $v_{i}$ are independent of inputs and mutually independent as well.

The maximum likelihood method is usually applied to estimate the parameters as described in [10]. We have also tested a more general SFA setting, such as using the translog production function and general Truncated Normal distribution for the inefficiency term but the results didn't differ much, and the extra terms were statistically insignificant, so we stick to the simple case.

As the basic SFA model is designed for a single output only, special procedures have to be applied to generalize the approach for more outputs. The first option described by [6] is to substitute the production function in the model by the so-called distance function. The input distance function is defined as

$$
d_{i}(x, y)=\max \left\{\rho: y \text { can be produced by } \frac{x}{\rho}\right\}
$$

The natural assumptions on the production possibility set imply that this function should be non-decreasing and concave in inputs. After some simplifications, the model for Cobb-Douglas functional form of $d_{i}(x, y)$ can be rewritten as

$$
-\ln x_{m i}=\beta_{0}+\sum_{j=1}^{m-1} \beta_{j} \ln \left(\frac{x_{j i}}{x_{m i}}\right)+\sum_{k=1}^{r} \gamma_{k} \ln y_{k i}+v_{i}-u_{i},
$$

where $u_{i}=\ln d_{i}(x, y)$. Unfortunately, the estimation of the distance function is not always as straightforward as it might seem. The first issue can occur in application of SFA models in general. It is the correlation between the explanatory variables and the model's error component, which would violate the basic assumption of the model. This problem can be solved using the method of instrumental variables. Another issue occurs if the estimated distance function does not meet the required property of monotonicity and concavity in inputs (unless there is additional constraint on the coefficients $\beta$ ). Because of these considerations, we also applied the approach suggested by Scippacercola et al., [20] based on the principal component analysis 
(PCA). We first estimate models for individual outputs separately, then combine the obtained inefficiencies into one matrix, where the $k$-th column contains the inefficiencies of all units with respect to the $k$-th output. If the first principal component of this matrix extracts enough of the original variability, we can use it as an estimate of inefficiency. The drawback of this approach is that using PCA, we can obtain both positive and negative values and the information on the total size of inefficiency is lost, so it can only be used for the ranking of the units. To get more robust results, we also used the third approach of scalarization computing the total efficiency as geomean of efficiencies for individual outputs.

\subsection{Data envelopment analysis}

Basic models of data envelopment analysis are used to evaluate the relative performance of decision making units (DMUs) in a homogeneous sample of $n$ units. The efficiency of DMUs is expressed on the basis of $m$ inputs and $r$ outputs.

If we denote the input and output vectors for $i$-th DMU by $x_{i}$ and $y_{i}, i=1, \ldots, n$, we can express the (input-oriented) efficiency of $\mathrm{DMU}_{q}$ by the optimal objective value of the linear program

$$
\begin{array}{ll}
\min _{\forall \theta_{q}, \lambda_{i}} \theta_{q}, & \\
\text { subject to } & \sum_{i=1}^{n} x_{i j} \lambda_{i} \leq \theta_{q} x_{q j}, \quad j=1, \ldots, m, \\
& \sum_{i=1}^{n} y_{i k} \lambda_{i} \geq y_{q k}, \quad k=1, \ldots, r, \\
& \lambda_{i} \geq 0, \\
\text { and } & \sum_{i=1}^{n} \lambda_{i}=1,
\end{array}
$$

where $\theta_{q}$ represents the necessary reduction of the inputs and the variable $\lambda_{i}, i=1, \ldots, n$ are the coefficients of the virtual unit projecting $\mathrm{DMU}_{q}$ on the efficient frontier. The last constraint corresponds to the variable returns to scale (VRS) assumption. Although the character of returns to scale in the area of transportation is subject to a scientific debate [25], most authors assume the presence of economies of scale in the aircraft industry [4]. Basic DEA models distinguish between orientation on inputs or outputs. They are called radial because they indicate the degree of proportional reduction of all inputs (or increase of outputs) to become effective for a given unit. However, there are groups of models whose formulation does not require model orientation. These models are referred to as additive models or SBM models (slack based measure) as their formulation is based on additional variables $s_{j}^{-}, j=1, \ldots, m, s_{k}^{+}, k=$ $1, \ldots, r$, expressing slacks of inputs and outputs.

As a representative of this group, the model proposed by Tone [22] was selected for our 
analysis (Tone's Slacks Based Measure model; SBMT model):

$$
\begin{aligned}
& \min _{\forall \lambda_{i}, s_{k}^{+}, s_{j}^{-}} \frac{1-\frac{1}{m} \sum_{j=1}^{m} \frac{s_{j}^{-}}{x_{q j}}}{1+\frac{1}{r} \sum_{k=1}^{r} \frac{s_{k}^{+}}{y_{q k}}}, \\
& \text { subject to } \quad \sum_{i=1}^{n} x_{i j} \lambda_{i}+s_{j}^{-}=x_{q j}, \quad j=1, \ldots, m, \\
& \sum_{i=1}^{n} y_{i k} \lambda_{i}-s_{k}^{+}=y_{q k}, \quad k=1, \ldots, r, \\
& s_{k}^{+} \geq 0, \quad k=1, \ldots, r, \\
& s_{j}^{-} \geq 0, \quad j=1, \ldots, m, \\
& \lambda_{i} \geq 0, \quad i=1, \ldots, n, \\
& \text { and } \quad \sum_{i=1}^{n} \lambda_{i}=1 \quad \text { (VRS) assumption }
\end{aligned}
$$

As many benchmarking studies aim to obtain a unique ranking of the DMUs, it is not desirable to use a method that identifies a large portion of the units as fully efficient. This situation can often occur when we use ordinary models, mainly when we use many inputs and outputs and assume variable returns to scale. So the SBMT model has been further modified [23] to the super SBMT model having more discriminatory power for the units identified as efficient by the basic model. The super-efficiency SBMT model removes the evaluated unit $\mathrm{DMU}_{q}$ from the set of DMUs and looks for its projection on the efficient frontier $\left(\mathrm{DMU}^{*}\right)$ determined by the remaining $n-1$ units. The super-efficiency measure is defined as the distance of the units $\mathrm{DMU}_{q}$ and $\mathrm{DMU}^{*}$ in their input and output space. The virtual inputs $x_{i}^{*}, i=1, \ldots, m$, and outputs $y_{k}^{*}, k=1, \ldots, r$, are determined by the fractional linear program

$$
\begin{array}{cll}
\min _{\forall \lambda_{i}, x_{j}^{*}, y_{k}^{*}} \frac{\frac{1}{m} \sum_{j=1}^{m} \frac{x_{j}^{*}}{x_{q j}}}{\frac{1}{r} \sum_{k=1}^{r} \frac{y_{k}^{*}}{y_{q k}}}, & \\
\text { subject to } & \sum_{i=1}^{n} x_{i j} \lambda_{i} \leq x_{j}^{*}, \quad j=1, \ldots, m, \\
& \sum_{i=1}^{n} y_{i k} \lambda_{i} \geq y_{k}^{*}, \quad k=1, \ldots, r, \\
& x_{j}^{*} \geq x_{q j}, & j=1, \ldots, m, \\
& y_{k}^{*} \leq y_{q k}, & k=1, \ldots, r, \\
& \lambda_{i} \geq 0, & i=1, \ldots, n, i \neq q, \\
& \lambda_{q}=0, & \\
& \sum_{i=1}^{n} \lambda_{i}=1 & .
\end{array}
$$

The last constraint corresponds to the variable returns to scale assumption. When applying the method to our data, we followed the two-phase procedure recommended by [8]: 
1. Use the basic SBMT model (without excluding the unit under evaluation from the set of DMUs in the model) to divide units into efficient and inefficient ones, for which we compute the SBMT efficiency values.

2. Compute the super-efficiency according to the super SBMT model 7 for efficient units from the first phase.

By this procedure, referred to as the (super)SBMT model we get values greater than 1 for efficient units and less than 1 for inefficient DMUs.

\subsection{Comparing efficiency across groups: program evaluation proce- dure}

In order to explore the effect of different forms of ownership on the performance of the airports, we wanted to control for the other factors. So we applied the program evaluation procedure outlined by Brockett and Golany [7] and Sueyoshi and Aoki [21]. The purpose of this procedure is to distinguish between the degree of inefficiency caused by the uneconomical operation of the units and that caused by belonging to a particular group. The procedure includes four steps:

1. Split the group of all DMUs $(j=1, \ldots, n)$ into $p$ subgroups consisting of $n_{1}, \ldots, n_{p}$ DMUs $\left(\sum_{i=1}^{p} n_{i}=n\right)$. Run DEA separately for the individual groups.

2. In each of the $p$ groups, adjust inefficient DMUs to their "level if efficient" values by projecting each DMU onto the efficiency frontier of its group.

3. Run a pooled DEA with all $n$ DMUs at their adjusted efficient levels.

4. Apply a statistical test (Mann-Whitney for two groups or Kruskal-Wallis for $p>2$ ) to the results of the previous step to determine if the groups have the same distribution of efficiency values within the pooled DEA set.

\section{Data for the analysis}

There are 1093 airports with assigned IATA ( International Air Transport Association) code in Europe, see Airport Database 2019 [3]. For our analysis, we intended to cover the 150 busiest European airports according to the number of passengers transported in 2018. The airport traffic report of the association Airports Council International shows that highest number of passengers came through London Heathrow Airport, followed by Charles Airport de Gaulle in Paris and Schiphol in Amsterdam [1]. Data collection proved to be quite problematic. No summary was available for many airports; therefore data were searched individually, but relevant information was missing in some cases. That is why we had to exclude 35 airports and consequentially, our data sample covers 115 of them. The map in Figure 1 shows all the airports considered initially for analysis. It is color-coded for airports with complete data and airports excluded from the study. We can see that almost every European country has at least one representative in the sample.

In our analysis, the output side is expressed by three variables, namely passengers, aircraft movements, and cargo. The number of runways, terminals, gates, and aircraft stands were selected for the inputs. The selection of relevant variables for the analysis was based on a literature review. The number of terminals was used twice (further, the capacity of terminals was used twice and the total area of terminals was used 9 times in different studies), the number of runways was used 7 times (plus 3 further times referring to their area and 4 times to their total length), boarding gates were analyzed 5 times, and aircraft stands 6 times (and 3 further times referring to their area). On the output side, 20 studies used the number of passengers, 18 


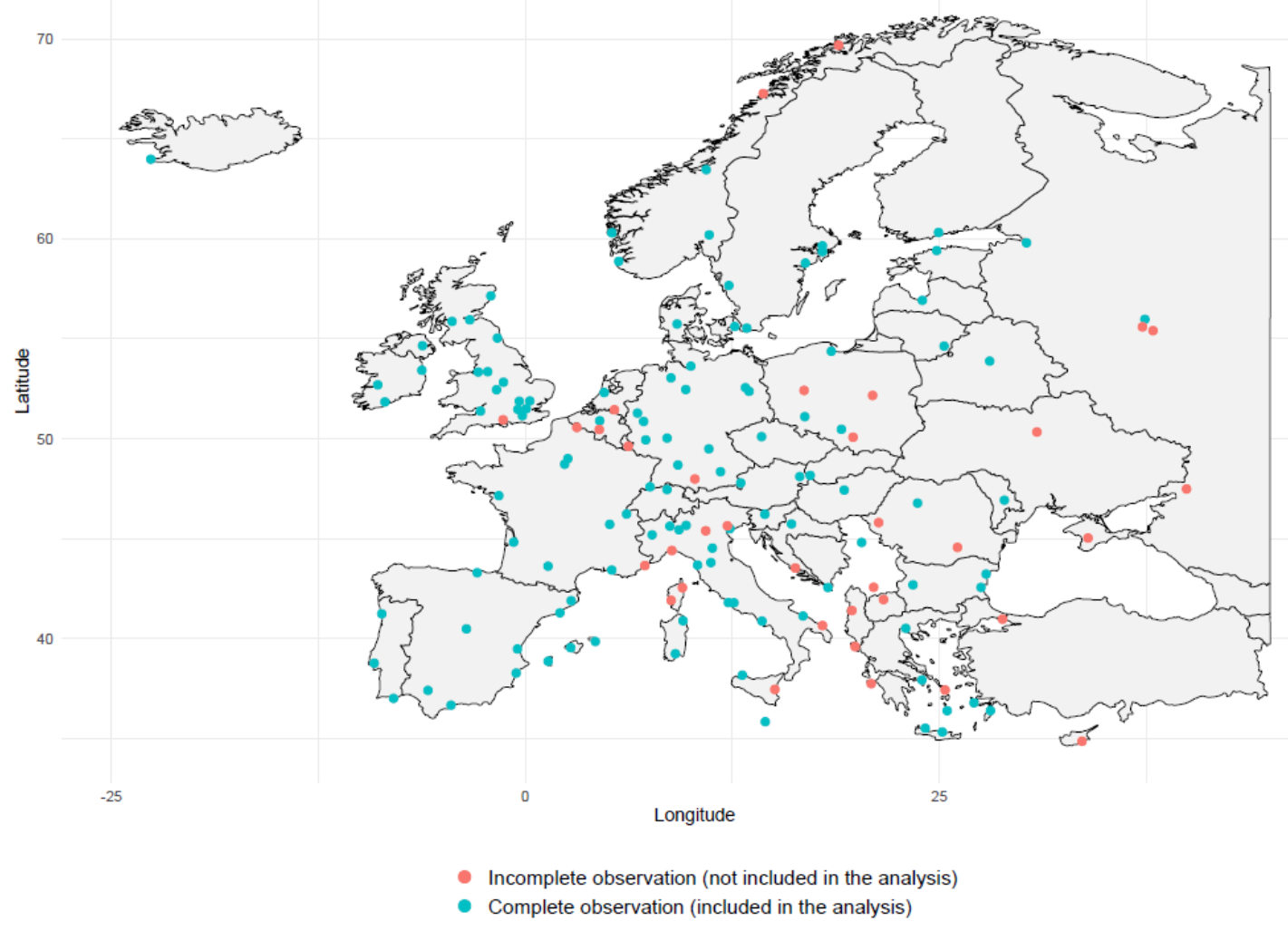

Figure 1: Map of airports locations

number of aircraft movements, 17 the total tuns of cargo. In addition to the characteristics we used, there are also sometimes other variables used, like total costs, staff, or check-in counters on the input side and revenues on the output side [12]. Descriptive statistics of inputs and outputs of units included in our study are in Table 1.

\begin{tabular}{lrrrrrrr}
\hline & Terminals & Runways & Gates & Stands & Passengers & Movements & Cargo [t] \\
\hline Minimum & 1.000 & 1.00 & 4.00 & 6.00 & 1677661 & 13195 & 51 \\
1st quartile & 1.000 & 1.00 & 14.50 & 24.00 & 4310005 & 42853 & 3800 \\
Median & 1.000 & 1.00 & 23.00 & 40.00 & 6962040 & 76995 & 18543 \\
Mean & 1.687 & 1.67 & 43.52 & 60.85 & 14309037 & 117317 & 141920 \\
3rd quartile & 2.000 & 2.00 & 53.00 & 75.00 & 17900050 & 149867 & 93922 \\
Maximum & 5.000 & 6.00 & 269.00 & 340.00 & 80124537 & 512115 & 2176389 \\
\hline
\end{tabular}

Table 1: Table 1: Descriptive statistics of inputs and outputs

\section{Results and discussion}

The methods described in Section 3 were applied on the data using the R packages deaR, frontier, and npsf. First we evaluated the SFA model for each output separately. The parameters were estimated by the maximum likelihood method. Table 5 shows the summary statistics of these simple SFA models, where the p-values are taken from the (asymptotic) normal distribution. In all three models, the logarithm of the number of terminals appears to be insignificant, while the other input variables appear to be significant. 


\begin{tabular}{c|cccccc}
\hline & \multicolumn{2}{|c}{ Passengers } & \multicolumn{2}{c}{ Movements } & \multicolumn{2}{c}{ Cargo } \\
\hline \hline Constant & 12.936 & $* * *$ & 8.492 & $* * *$ & 4.117 & $* * *$ \\
& $(0.189)$ & & $(0.196)$ & & $(0.864)$ & \\
$\ln$ (Terminals) & -0.007 & & -0.037 & & -0.493 & \\
& $(0.084)$ & & $(0.079)$ & & $(0.341)$ & \\
$\ln$ (Runways) & 0.290 & $* * *$ & 0.181 & $* *$ & 0.705 & $*$ \\
& $(0.092)$ & & $(0.085)$ & & $(0.360)$ & \\
$\ln$ (Boarding_gates) & 0.558 & $* * *$ & 0.592 & $* *$ & 0.770 & $*$ \\
& $(0.076)$ & & $(0.071)$ & & $(0.283)$ & \\
$\ln$ (Aircraft_stands) & 0.383 & $* * *$ & 0.283 & $* *$ & 1.221 & $*$ \\
& $(0.078)$ & & $(0.073)$ & & $(0.299)$ & \\
\hline
\end{tabular}

Table 2: Estimations of separate SFA models; standard deviations in brackets; *,**,*** denotes statistical significance of $10 \%, 5 \%, 1 \%$

We focused on model diagnostics and checked the distribution assumptions for both error members in the model. Figure 2 shows histograms and the probability density of the individual terms. Using the Kolmogorov-Smirnov test, we do not reject the null hypothesis about the normality of the error component. The inefficiency component should follow a Half-Normal distribution, and according to the graphs, it seems that this assumption should be met for all three models. So we can express the individual efficiencies and subsequently apply a suitable method of their aggregation because we are most interested in approaches that take into account all three outputs together so they can be compared with DEA models.

As a first approach for multiple inputs, the distance function (4) was used. The logarithm of the number of terminals was chosen as the normalization variable; however, the same results would be obtained for any other input. Again, we have checked the assumptions about the distribution of error and inefficiency component terms. However, all the model parameters appeared to be insignificant; it is therefore possible that some of the other model assumptions were not met. The other two possible approaches directly aggregate the efficiencies obtained using simple SFA models. First, we applied the PCA method to individual efficiencies. The obtained first main component covered about $58 \%$ of the total variability and efficiency of outputs were represented as follows: number of passengers with a coefficient -0.69 , number of aircraft movements by a coefficient -0.70 , and cargo with a coefficient -0.19 . We checked the direction of correlation of the first principal component with the original efficiencies, and since this correlation was negative, we multiplied the PCA scores by -1 to maintain the same interpretation as the efficiency rate - the higher the value of the main component, the more efficient the airport. Now we could arrange the airports from the most to the least efficient. The last approach was probably the simplest of all mentioned so far, it was based on a geometric mean of efficiencies obtained by simple models.

We compare the results using Spearman correlation coefficients, which is shown in Figure 3. If we look at the correlations of simple models, we can see that the model for the number of passengers is strongly correlated with the model for aircraft movements, but their correlation with the model for cargo is weak. This may be due to the correlations between the inputs themselves. Benchmarking of airports using the cargo model is therefore quite different from the other two. The results of distance function and PCA models are strongly correlated with the individual models for the number of passengers and the number of aircraft movements, which again corresponds to the correlations between simple models. The correlation between all methods for multiple outputs is relatively strong in general. It is surprising that even a simple concept of geometric mean can compete with more sophisticated approaches.

It is know that basic DEA models can identify several DMUs as fully efficient. As expected, the model (5) identified only 22 airports as inefficient. The non-radial model defined by equation 

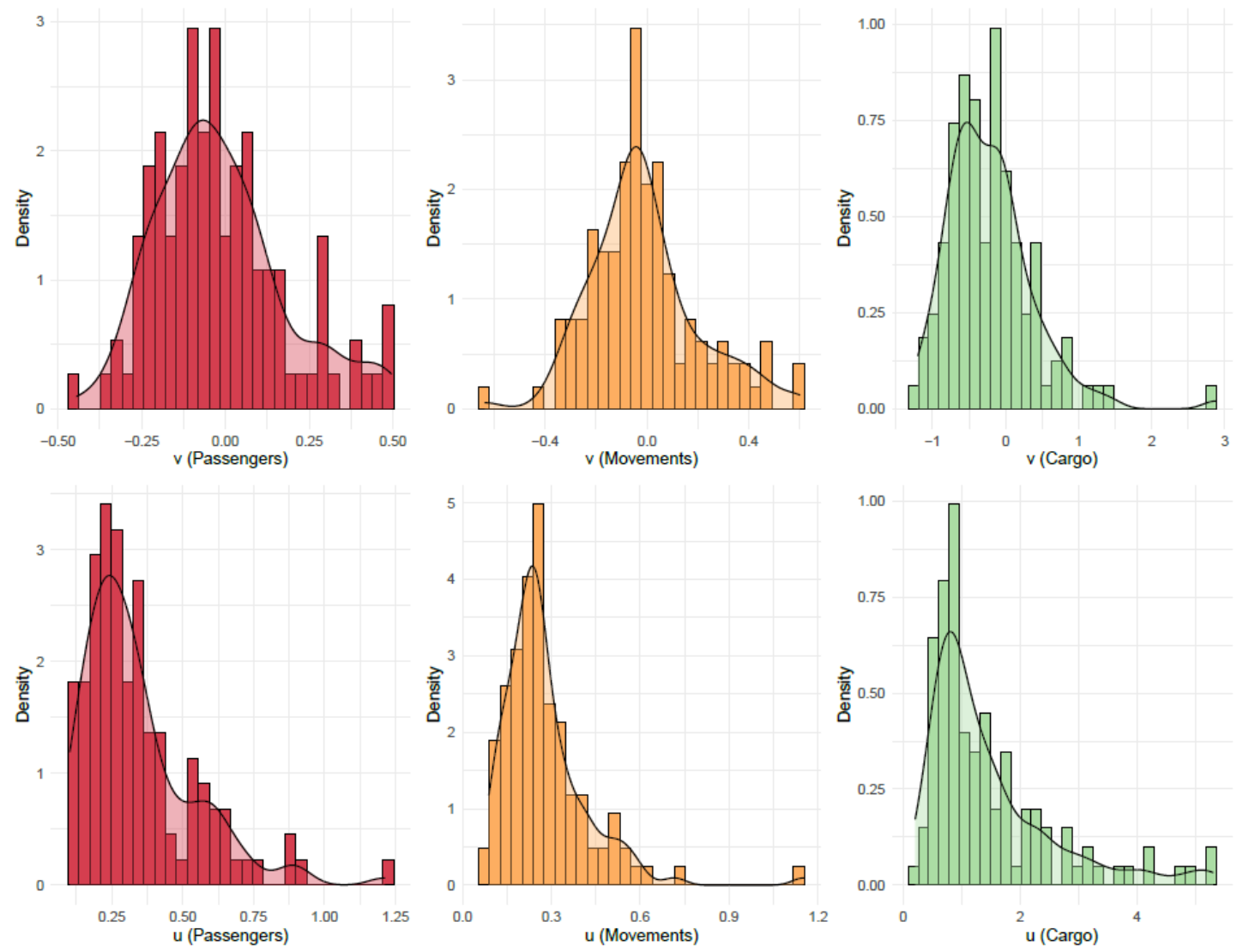

Figure 2: Distribution of error terms of simple SFA models

(6) gave better results with 77 inefficient units. But there is still some space for improving the results because we cannot rank the units with efficiency equal to 1 . So we finally evaluated the performance of the airports by the two-stage procedure combining the results of (6) with the super-efficiency model (7). The rank correlations of DEA scores with the SFA results are shown in Figure 4.

We can see that the basic DEA model scores are poorly correlated with all the other results. The main reason is probably the low discriminatory power of this model. The best agreement of non-parametric and parametric approaches (with correlation equal to 0.64) is achieved using (super)SBMT model of DEA and the geometric mean of individual SFA scores. So for further comparison, we select these two methods. The top ten performers identified by particular methods are listed in Table 5. 


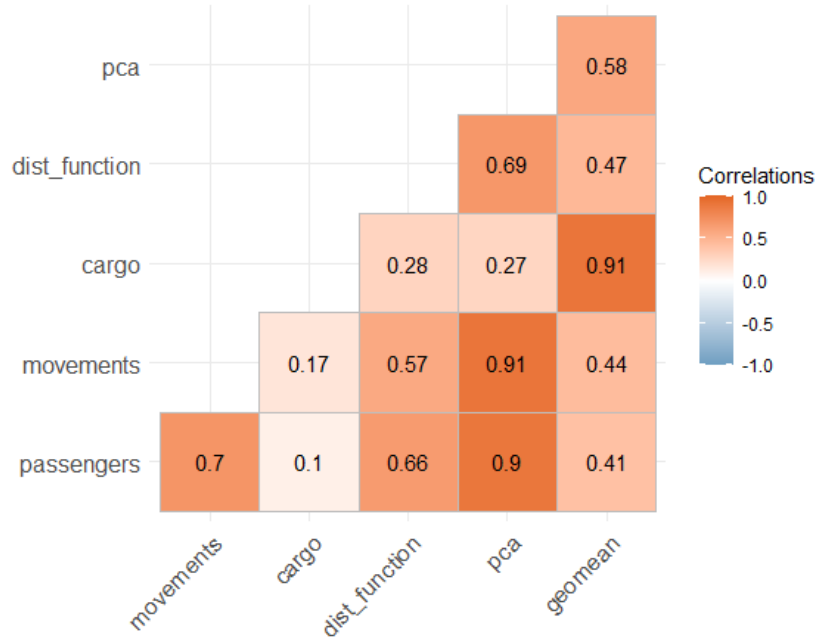

Figure 3: Spearman correlations of SFA results

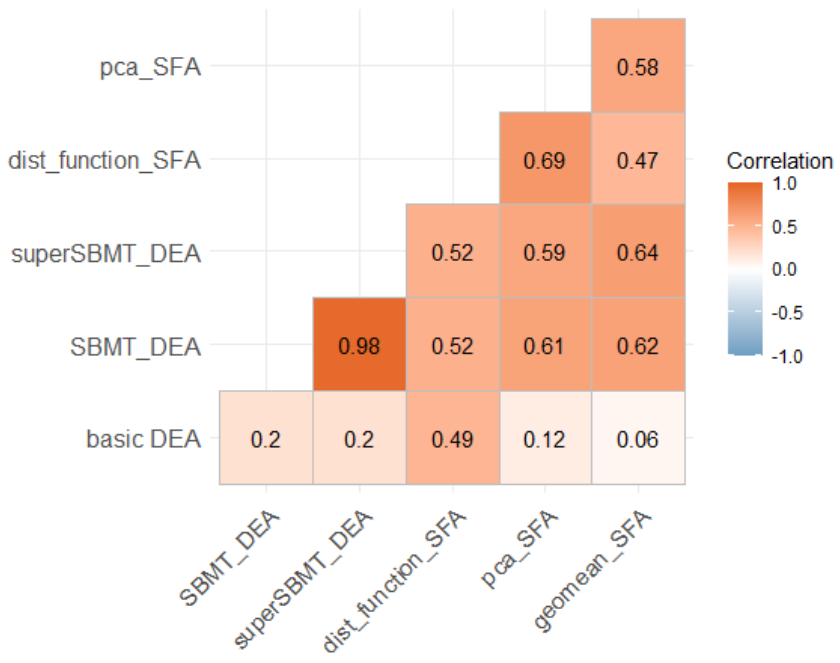

Figure 4: Spearman correlations of DEA and SFA results

\begin{tabular}{lllllll}
\hline Rank & DEA: (super)SBMT & TE & Size rank & SFA: Geometric mean & TE & Size rank \\
\hline 1 & Frankfurt- Hahn & 1.321 & 111 & Reykjavík & 0.826 & 46 \\
2 & London Heathrow & 1.266 & 1 & Zagreb & 0.789 & 91 \\
3 & Amsterdam Schiphol & 1.258 & 3 & London Heathrow & 0.744 & 1 \\
4 & Reykjavík & 1.241 & 46 & Bologna & 0.739 & 54 \\
5 & Kos & 1.234 & 101 & Belfast & 0.735 & 7 \\
6 & Santorini & 1.181 & 108 & Moscow Sheremetyevo & 0.734 & 9 \\
7 & London Stansted & 1.163 & 19 & Naples & 0.730 & 45 \\
8 & London Luton & 1.160 & 32 & Lisbon & 0.728 & 16 \\
9 & Chania & 1.156 & 97 & Milan Orio al Serio & 0.722 & 37 \\
10 & East Midlands & 1.153 & 80 & Belgrade & 0.719 & 71 \\
\hline
\end{tabular}

Table 3: Technical efficiencies of top ten performers

Only two airports are on both top ten lists. London Heathrow, with 80 million of transported passengers, is the busiest European airport, and Reykjavík - Keflavík is the main airport for 
international connections to the whole of Iceland. It seems that smaller airports are preferred when we apply the DEA method; the best airport Frankfurt-Hahn is actually one of the smallest in our sample. It has the advantage of geographic location between Frankfurt and Luxembourg, about $120 \mathrm{~km}$ to both cities, so it represents a cheaper alternative to Frankfurt Airport. Other smaller airports on the list (Kos, Santorini, Chania) serve mainly for seasonal flights of charter operators. But, on the other hand, big international hubs such as London Heathrow and Amsterdam Schiphol occupy the top positions of the DEA ranking. Concerning SFA results, the smallest airport among the top performers is Zagreb which is the second best. Zagreb airport is the largest and busiest international airport in Croatia, the Croatian flag carrier Croatia Airlines hub and a focus city for charter operator Trade Air.

Using these results, we analyzed the effect of ownership on airport efficiency measures using the procedure presented in subsection 3.3. We have classified the airports into three groups: Fully public (including Fully public - corporatized and Fully public - part of public administration), Fully private, and Mixed group (including Mostly public, Mostly private, Equally public and private). Our sample comprises 21 fully private airports, 44 fully public, and 50 airports in mixed ownership. A preview of the DEA and SFA results for 30 busiest airports together with the ownership cathegory can be found in Table 5 .

\begin{tabular}{llcccc}
\hline & & \multicolumn{2}{c}{ DEA } & \multicolumn{2}{c}{ SFA } \\
\multicolumn{1}{c}{ Name } & Ownership & TE & rank & TE & rank \\
\hline London Heathrow & Fully private & 1.266 & 2 & 0.744 & 3 \\
Paris Charles de Gaulle & Mostly public & 1.011 & 36 & 0.620 & 39 \\
Amsterdam Schiphol & Mostly public & 1.258 & 3 & 0.568 & 55 \\
Frankfurt am Main & Mostly public & 1.152 & 11 & 0.683 & 20 \\
Madrid & Mostly public & 0.310 & 64 & 0.401 & 91 \\
Barcelona & Mostly public & 0.222 & 71 & 0.370 & 97 \\
Munich & Fully public - corporatized & 1.071 & 18 & 0.545 & 61 \\
London Gatwick & Fully private & 1.089 & 14 & 0.500 & 75 \\
Moscow Sheremetyevo & Mostly public & 1.054 & 22 & 0.734 & 6 \\
Rome Fiumicino & Mostly private & 0.396 & 55 & 0.548 & 59 \\
Orly & Mostly public & 1.001 & 38 & 0.482 & 80 \\
Dublin & Fully public - corporatized & 0.396 & 56 & 0.620 & 38 \\
Zurich & Mostly private & 0.483 & 49 & 0.630 & 36 \\
Copenhagen & Mostly private & 0.505 & 48 & 0.618 & 41 \\
Palma de Mallorca & Mostly public & 0.027 & 99 & 0.333 & 99 \\
Lisbon & Fully private & 1.071 & 17 & 0.728 & 8 \\
Manchester & Mostly public & 0.299 & 65 & 0.616 & 43 \\
Oslo & Fully public - corporatized & 1.078 & 15 & 0.660 & 27 \\
London Stansted & Mostly public & 1.163 & 7 & 0.695 & 14 \\
Vienna & Mostly private & 0.421 & 52 & 0.615 & 44 \\
Stockholm Arlanda & Fully public - corporatized & 0.175 & 79 & 0.485 & 79 \\
Brussels & Mostly private & 0.705 & 40 & 0.572 & 53 \\
Malpensa & Mostly public & 0.509 & 47 & 0.535 & 64 \\
D usseldorf & Equal public and private & 0.162 & 83 & 0.488 & 77 \\
Athens & Mostly public & 1.034 & 26 & 0.691 & 17 \\
Berlin Tegel & Fully public - corporatized & 0.314 & 63 & 0.539 & 63 \\
Helsinki & Fully public - corporatized & 1.037 & 25 & 0.698 & 13 \\
Malaga & Mostly public & 0.010 & 106 & 0.253 & 106 \\
Saint Petersburg Pulkovo & Fully private & 1.014 & 34 & 0.375 & 94 \\
Geneva & Fully public - corporatized & 1.034 & 27 & 0.682 & 22 \\
\hline & & & & &
\end{tabular}

Table 4: Technical efficiencies of 30 busiest airports 
In Figure 5 we can see two graphs showing the boxplots of DEA efficiency for individual types of ownership. The black line in the box diagram corresponds to the median, and the black dot to the mean efficiency. The graph on the left shows the situation when the program evaluation procedure of subsection 3.3 was not used. It is therefore a comparison of efficiencies between different ownership groups using an overall model. If we perform the Kruskal-Wallis test for these values, we obtain a $p$-value of 0.762 , and thus we do not reject the null hypothesis that there is no effect of ownership on efficiency. However, this evaluation includes possible aspects of the uneconomical operation of individual airports. The boxplot on the right side of Figure 5 is obtained by the proposed procedure for group comparison using (super)SBMT models. The differences between groups are more pronounced. In this case, the Kruskal-Wallis test returns a $p$-value of 0.064 , and therefore we reject the null hypothesis that there is no effect of airport ownership on the efficiency level at the significance level of $10 \%$. On average, privately owned airports seem to be the most efficient, followed by a group of mixed-owned airports, and public airports appear to be the least efficient.

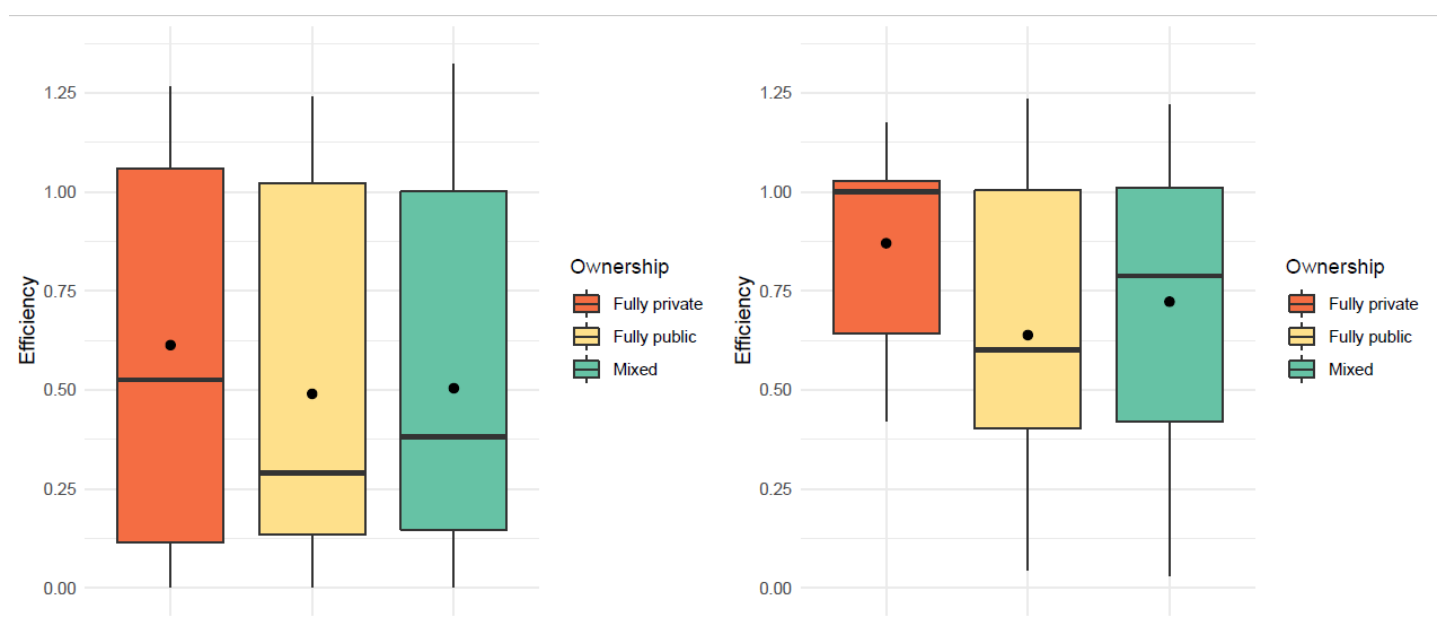

Figure 5: Efficiency comparison; on the left model for the original data, on the right model for the corrected values

\section{Conclusion}

In this paper, we have evaluated the performance of 115 European airports. We have based our computations on five inputs, including the number of terminals, runways, boarding gates, and aircraft stands, and three outputs represented by the number of passengers, aircraft movements, and tons of cargo. We applied SFA model with the Cobb-Douglas production function and Normal/Half-Normal distribution of error and inefficiency terms. We employed three different scalarisation techniques for the efficiency scores obtained using the individual outputs, namely distance function, principal component analysis, and geometric mean. The usage of distance function is restricted by rather demanding assumptions, so it cannot be recommended as a generic method. The disadvantage of the approach based on PCA is that it provides no information on the absolute inefficiency level. Another problem may arise when the main component does not extract enough variability of inefficiency terms. So, for its simplicity and universal usage, we selected the last option based on geometric average as the most suitable SFA multi-output model. Next, we evaluated airport performance non-parametrically using three DEA models (basic model for variable returns to scale, Tone's additive model, and the superefficiency SBMT model). The last option was selected as the most appropriate to get a unique ranking of DMUs. We confronted results obtained parametrically and non-parametrically and 
realized that there is a strong positive association between SFA and DEA scores (Spearman correlation of 0.64). We used these obtained results to explore how airports' performance is affected by their form of ownership. Applying the naive approach comparing the efficiency scores of individual airports, we found no statistically significant difference in the performance of airports with different forms of ownership. After applying an advanced approach controlling for the influence of inefficiencies caused by individual managerial failures we obtained quite contrasting results identifying private airports as the most efficient and public airports as the least efficient.

The limitation of similar studies is given by the sensitivity of results to the methodology employed. The values of the effective scores are influenced by the model specification including the selection of a particular model from the portfolio of parametric or non-parametric approaches and determination of inputs and outputs, economies of scale, etc. In addition, some annual reports on airport performance show evidence of inconsistencies over time and there is also high possibility of the occurrence of other biases caused e.g. by longer-term effects of lumpy capital investments. [14]. This paper aims at getting more robust results by combining findings obtained by different models. Nevertheless the topic deserves further examination; one possible way of extending the study is to cover longer time period.

\section{References}

[1] ACI EUROPE. (2018). Airport traffic report (December, Q4, H2 \& Full Year 2018). Available from: https://www.aci- europe.org/policy/positionpapers.html [Accessed 15-07-19]

[2] Airports Council International (2019). Annual Traffic Data. Available from: https://aci.aero/datacentre/annual-traffic-data/ [Accessed 20-04-21]

[3] AIRPORTDATABASE. (2019). Available from: https://airportdatabase.net/europeairports.html. [Accessed 2019-07-15].

[4] Adler, N., and Berechnam, J. (2001). Measuring airport quality from the airlines' viewpoint: an application of data envelopment analysis. Transport Policy, 8(3), 171-181. doi: 10.1016/S0967070X(01)00011-7

[5] Barros, C.P. and Dieke, P.U. (2007). Performance evaluation of Italian airports: a data envelopment analysis. Journal of Air Transport Management, 13(4), 184-191. doi: 10.1016/j.jairtraman.2007.03.001

[6] Bogetoft P. \& Otto L. (2011). Benchmarking with DEA, SFA, and R. New York: Springer.

[7] Brockett, P.L. and Golany B. (1996). Using rank statistics for determining programmatic efficiency differences in data envelopment analysis. Management Science, 42(3), 466-472. doi: $10.1287 /$ mnsc. 42.3 .466

[8] Dlouhý, M., Jablonský, J. and Zýková, P. (2019). Analýza obalu dat. Praha: Professional publishing.

[9] Gillen, D. (2010). The evolution of airport ownership and governance. Journal of Air Transport Management, 17(1), 3-13. doi: 10.1016/j.jairtraman.2010.10.003

[10] Kumbhakar, S. C., Lovell, C. A. K. (2000). Stochastic Frontier Analysis. Cambridge: Cambridge University Press.

[11] Liebert, V. (2011). Airport Benchmarking: An Efficiency Analysis of European Airports from an Economic and Managerial Perspective. Doctoral thesis. Bremen: Jacobs University. https://dnb.info/1035211297/34

[12] Liebert, V. and Niemeier H. M. (2013). A Survey of Empirical Research on the Productivity and Efficiency Measurement of Airports. Journal of Transport Economics and Policy, 47, 157-189. https://www.jstor.org/stable/24396267

[13] Lin, L.C. and Hong, C.H. (2006). Operational performance evaluation of international major airports: an application of data envelopment analysis. Journal of Air Transport Management, 12(6), 342-351. doi: 10.1016/j.jairtraman.2006.08.002

[14] Morrison, W. G. (2009). Understanding the complexities and challenges of airport performance benchmarking. Journal of Airport Management, 3, 145-158. 
https://hstalks.com/article/380/understanding-the-complexities-and-challenges-of-a/

[15] Oum, T.H., Adler, N. and Yu, C. (2006). Privatization, corporatization, ownership forms and their effects on the performance of the world's major airports. Journal of Air Transport Management, 12(3), 109-121. doi: 10.1016/j.jairtraman.2005.11.003

[16] Oum, T.H., Yan, J. and Yu, C. (2008). Ownership forms matter for airport efficiency: A stochastic frontier investigation of worldwide airports. Journal of Urban Economics, 64(2), 422-435. doi: 10.1016/j.jue.2008.03.001

[17] Parker, D. (1999). The performance of BAA before and after privatisation: A DEA study. Journal of Transport Economics and Policy, 33(2), 133-145. https://www.jstor.org/stable/20053801

[18] Pels, E., Nijkamp, P., and Rietveld, P. (2001). Relative efficiency of European airports. Transport Policy, 8(3), 183-192. doi: 10.1016/S0967-070X(01)00012-9

[19] Pels, E., Nijkamp, P., and Rietveld, P. (2003). Inefficiencies and scale economies of European airport operations. Transportation Research Part E: Logistics and Transportation Review, 39(5), 341-361. doi: 10.1016/S1366-5545(03)00016-4

[20] Scippacercola, S., and Sepe, E. (2014). Principal component analysis to ranking technical efficiencies through stochastic frontier analysis and DEA. Journal of Applied Quantitative Methods, 9(4), 1-9. http://www.jaqm.ro/issues/volume-9, issue-4/1_SCIPPACERCOLA_SEPE.php

[21] Sueyoshi, T., and Aoki, S. (2001). A use of a nonparametric statistic for DEA frontier shift: the Kruskal and Wallis rank test. Omega, 29(1), 1-18. doi: 10.1016/S0305-0483(00)00024-4

[22] Tone, K. (2001). A slacks-based measure of efficiency in data envelopment analysis. European Journal of Operational Research, 130(3), 498-509. doi: 10.1016/S0377-2217(99)00407-5

[23] Tone, K. (2002). A slacks-based measure of super-efficiency in data envelopment analysis. European Journal of Operational Research, 143(1), 32-41. doi: 10.1016/S0377-2217(01)00324-1

[24] Vogel, H. A. (2006). Impact of privatisation on the financial and economic performance of European airports. Aeronautical Journal, 110(1106), 197-213. doi: 10.1017/S0001924000001184

[25] Xu, K., Windle, R., Grimm, C. and Corsi, T. (1994). Re-Evaluating Returns to Scale in Transport. Journal of Transport Economics and Policy, 28(3), 275-286. https://www.jstor.org/stable/20053046 